\title{
APPLICATION OF THREE-DIMENSIONAL SCENE TECHNOLOGY IN LAND MANAGEMENT
}

\author{
G.B. He, X.D. Zhang, R. Zhang \\ Aerial Photogrammetry and Remote Sensing Group Co., LTD, Shaanxi, China-505518576@qq.com
}

Commission V, WG V/7 \& Commission IV, WG IV/6

KEY WORDS: Three-Dimensional Scene, Land Management, Fly View, Oblique Photography, Sunshine Analysis, Visual Analysis, Flood Analysis

\begin{abstract}
:
The traditional two-dimensional technology is mainly used to describe and analyze the plane position and mutual relationship of geographical entities, and the land use is developing towards the three-dimensional trend; facing the new trend, the traditional twodimensional technology cannot meet the requirements of the three-dimensional land management. In this paper, the characteristics of three-dimensional technology are described in detail, and the applicability of three-dimensional technology to land management is analyzed. Finally, the application effect of three-dimensional technology in land management is verified through the actual project.
\end{abstract}

\section{INTRODUCTION}

With the development of land use to three-dimensional and complex, land management urgently needs to change from plane management to three-dimensional management mode. However, due to the unprecedented development of sensor, platform and processing software technology of three-dimensional data collection, the acquisition of real three-dimensional land model is easier than ever (Guo r.z, 2018). three-dimensional technology has attracted much attention because of its ability to fully perceive large-scale, high-precision, high-definition complex scenes, acquire high-resolution digital ground model, realistic Orthophoto Image, fine 3D city model and other measurement products. The current two-dimensional land management technology aims to describe, analyze and manage the information of the plane position, relationship and state of the surface, such as the investigation and statistics of the plane land parcel and its use, the evaluation and planning of the surface resources of the land, etc., which is difficult to support the quantitative positioning and analysis management of the three-dimensional extension parts outside the surface (Qin R, 2016); the threedimensional real-world technology not only provides different forms of data for land management As a new method of geometric analysis of land elements based on three-dimensional and high detail, it goes beyond the analysis boundary of traditional two-dimensional Technology (Zhang y.l., 1997).

This paper first reviews the background of 3D land management, and discusses the feasibility of land management based on 3D real scene technology from three aspects: the demand of architectural planning for 3D real scene technology, tilt photography technology and the support of the corresponding processing software development for 3D real scene technology. Finally, through a specific project application in Xi'an, the author puts forward the method Verification.

\section{FEASIBILITY ANALYSIS of 3D LAND MANAGEMENT}

\subsection{The Urgent Need of Three-dimensional City}

Several urban planning trends, as well as some political and historic considerations, are presently generating the need for legal recognition of three-dimensional property units. The traditional legal doctrine in all legal systems assumes vertical merger of ownership of all land strata. Several urban planning trends are presently generating, and will continue to generate in the future, the need for legal recognition of three-dimensional property units. The condominium phenomenon creates independent land units (Encyclopedia). The formation of multilevel mega-structures in the urban space and the development of three-dimensional and multi-level traffic and transport patterns, both above and below ground level (Birat), leads to the creation of functional and three-dimensional property units in an unconventional geometric forms. It could be seen in the large cities of the United States since the first decades of the twentieth century. Both worldwide and in the State of Israel a planning trend towards greater utilization of underground space is taking shape, accompanied by the minimizing of damage to the environment, to the landscape and to the rights of owners of above-ground land, while utilizing the advantages of the underground in terms of protection or isolation against weather conditions (HAIM SANDBERG, 2001).

\subsection{Current Situation of 3D Modeling}

In the process of data acquisition of building digital 3D model, tilt photography has the advantages of low cost, easy operation, full color, high fidelity and so on (LV. X.w., 2017). Tilt photogrammetry technology can fully perceive and collect the ground feature information of complex scenes in a fast, largescale and high-resolution way, and the data results generated by efficient data collection equipment and professional data processing process can directly reflect the appearance, position, height and other attributes of the ground features, providing guarantee for the real effect and geometric accuracy (Deng. Y., 2016).

\section{PROJECT APPLICATION}

\subsection{Project Background}

Compared with the traditional two-dimensional orthophoto image, the real-world three-dimensional image can observe the objects from many angles, and reflect the actual situation of the objects more truly. The three-dimensional scene system integrates abundant land information and basic geographic information, provides intuitive three-dimensional scene, and can 
realize the functions of three-dimensional calculation, location planning, editing and analysis. Compared with the traditional two-dimensional images, the real scene three-dimensional construction of the geographical scene is simple and intuitive, even non-professionals are easy to interpret and recognize (Deng.Y.,2016).

According to the needs of this project, we use the 3D real scene technology to obtain and process the 3D data of this area through the method of tilt photography. Then we use the flight control software independently developed by coal airlines to build the model of the planned building, and carry out sunshine analysis, visual field analysis, flood analysis. The analysis results fully meet the requirements of government land management and residents' living Room lighting, ventilation, visual understanding of the needs of the situation.

\subsection{Overall Flow Chart of the Project}

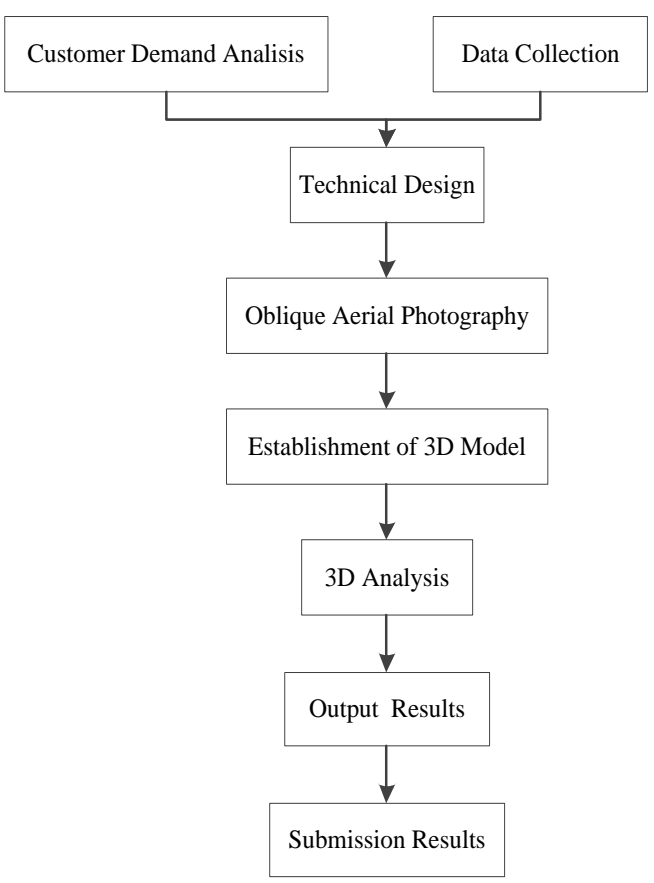

Figure 1.Work flow chart

\subsection{Implementation of the Project}

The data acquisition of this project adopts helicopter as the aerial camera carrying platform, and the aerial camera has used swdc-5 tilt aerial camera.

\begin{tabular}{|c|c|c|}
\hline Device Name & Device Type & Manufacturer \\
\hline Little squirrel h125 & Helicopter & Airbus \\
\hline $\begin{array}{c}\text { SWDC-5 } \\
\text { (Bring IMU) }\end{array}$ & $\begin{array}{c}\text { Tilt digital aerial } \\
\text { camera }\end{array}$ & $\begin{array}{c}\text { Four dimensional } \\
\text { vision dimensional } \\
\text { vision }\end{array}$ \\
\hline
\end{tabular}

Table 1. Parameter table of tilt photography instrument Tilt photography is as follows:

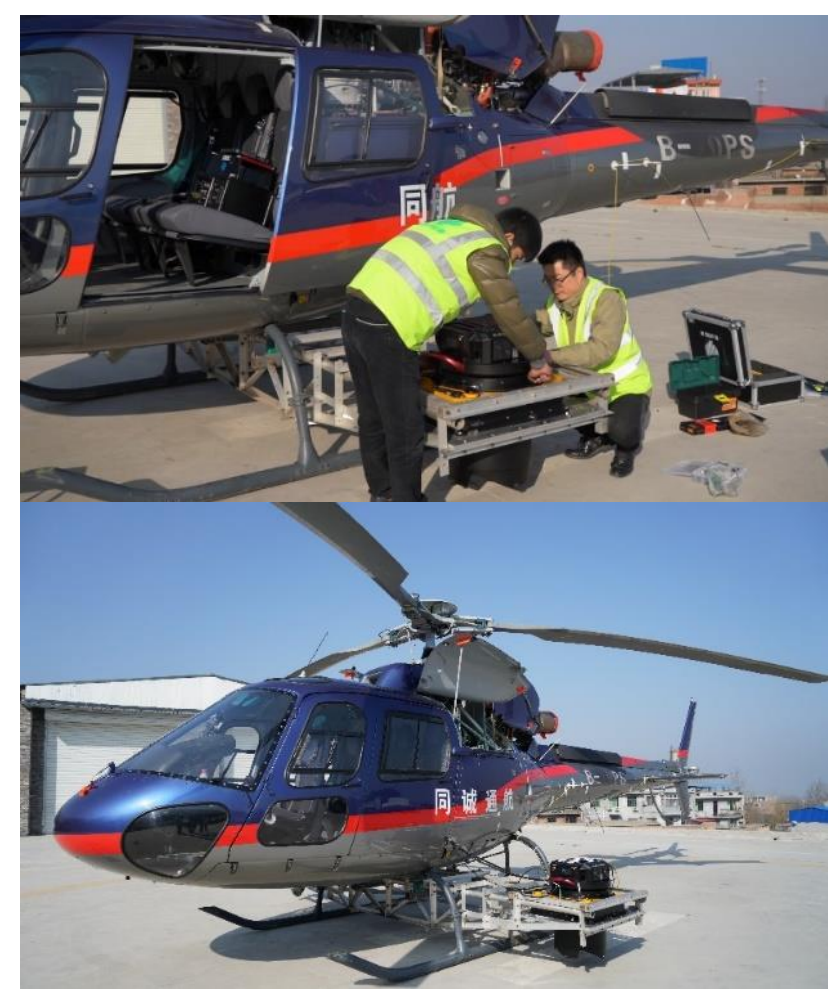

Figure 2.Implementation of aerial photography flight

After obtaining the 3D image, we processed the data and established the $3 \mathrm{D}$ model as follows:

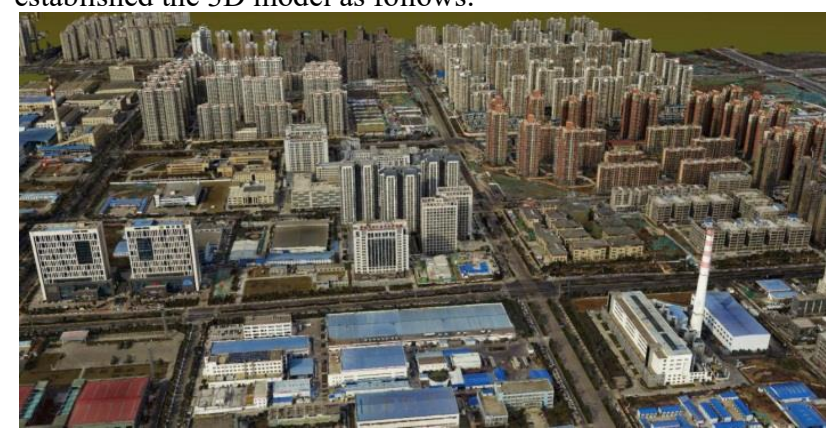

Figure 3.Three-dimensional model

After detailed investigation, the location of the proposed new building is as follows:

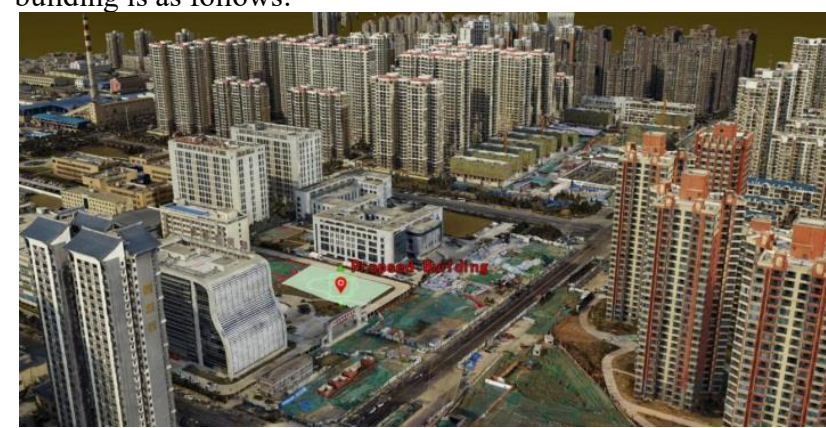

Figure 4.Location of proposed building

Add the building model as follows: 


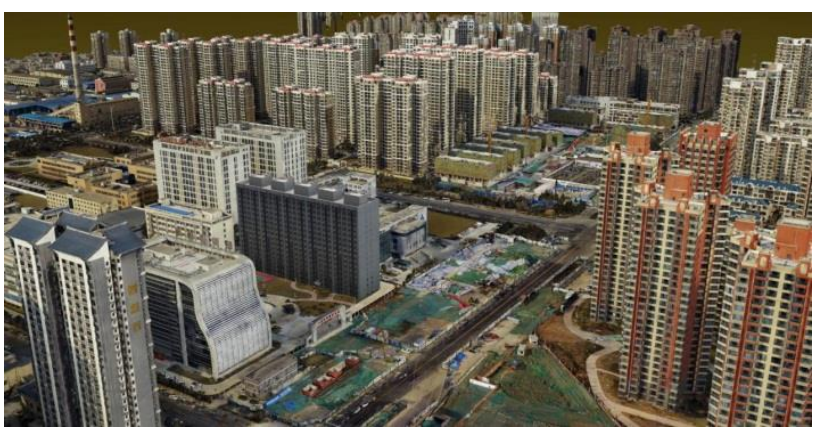

Figure 5.Three-dimensional model of the proposed building

After the completion of the above work, the sunshine analysis and visual field analysis of the proposed building are carried out by using the software "Fly View" developed by coal airlines. The detailed analysis is as follows:

3.3.1 Sunshine Analysis: Day lighting right refers to the right of the house owner to obtain appropriate light source from the outside. In this project, the light of the building to be built may be affected by the adjacent buildings, and after the completion of the building construction, it may also affect the day lighting of the surrounding buildings. In order to make the daylighting of the new building and the surrounding buildings reach a relative balance as far as possible, we are in favor of The sunshine analysis is carried out by using the software of "flying crane". Four seasons are selected, namely spring, summer, autumn and winter. The sunshine analysis is carried out at 8:00 a.m., 12:00 p.m. and 6:00 p.m. in each season. The simulation results are as Figure 6.Analysis of sunshine in different seasons.

After analysis, in the design scheme of the building, the lighting in the morning, noon and afternoon of summer and autumn is better than the relevant standards, and the lighting in the morning and afternoon of spring and winter is poor, which can barely reach the relevant standards. After analysis, the lighting situation after the building is completed is described quantitatively, which provides image data support for land planning and management.
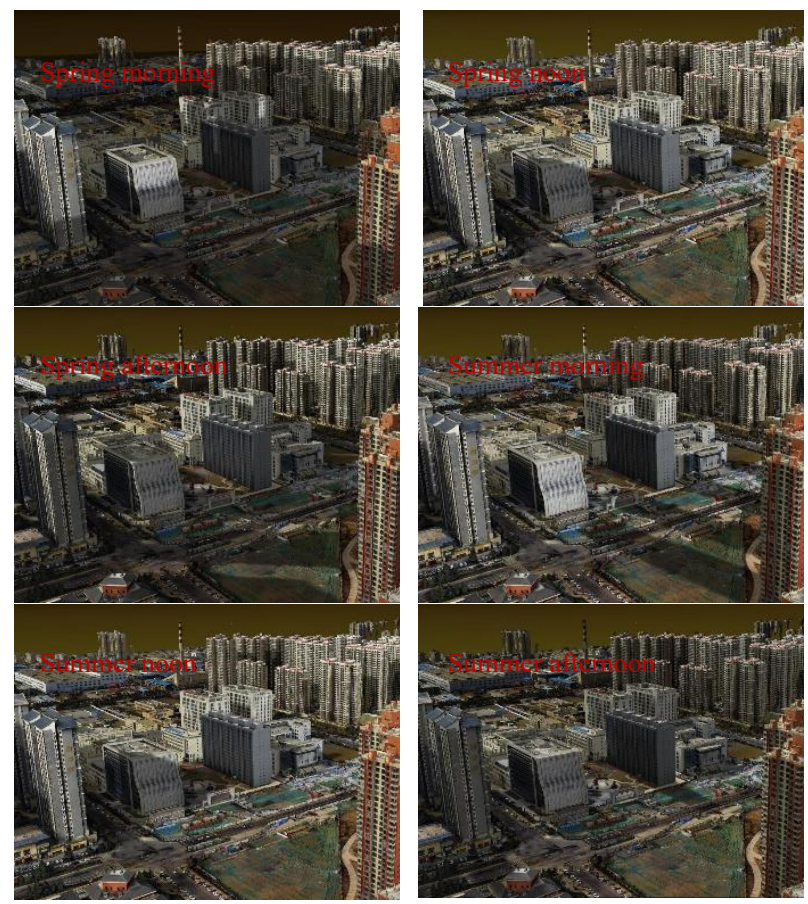
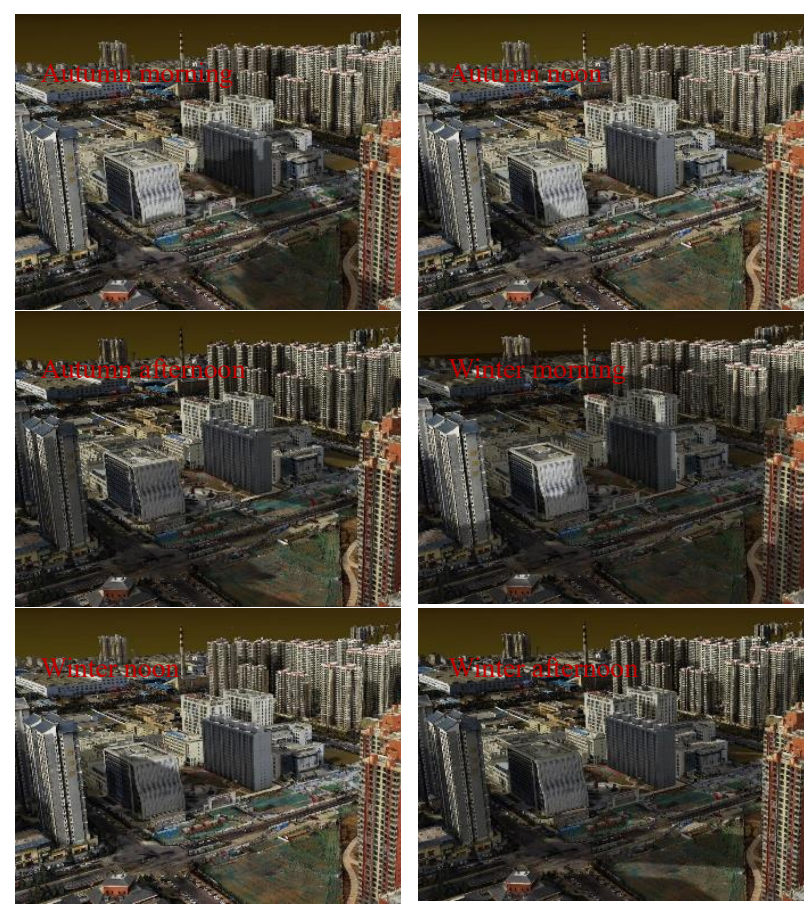

Figure 6.Analysis of sunshine in different seasons

3.3.2 Visual Analysis: Visual field refers to the specific location of a point as a viewpoint to analyze the coverage of the point's visual field; visual field is an important indicator of the quality of the house. We use the fly by wire software to analyze the visual field of the building and vividly show the scope of the building's visual field. The analysis results are as follows:

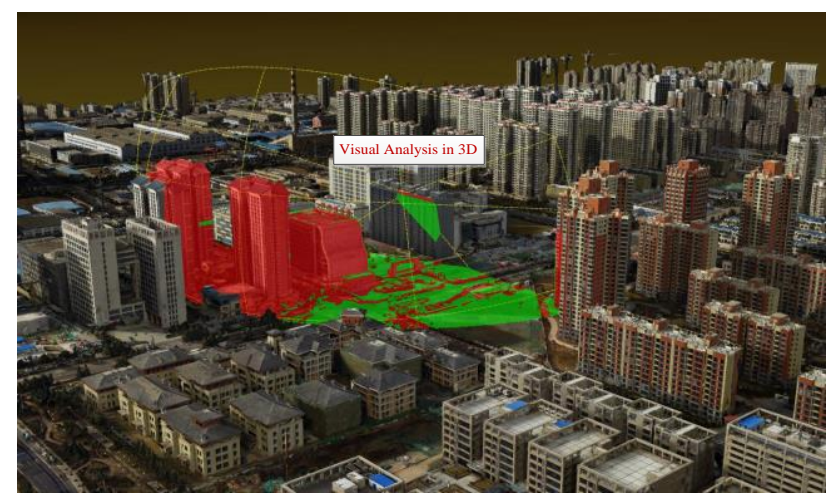

Figure 7. Visual Analysis

In the analysis results, the green part represents visible, and the red part represents invisible. After analysis, it can vividly express the situation of the visible vision of the building and meet the requirements of customers for the vision analysis.

3.3.3 Flood Analysis: In urban land management, it is very important to analyze the impact of heavy rain and flood on the city. We simulate the impact of different situations of heavy rain and flood on buildings with the help of the flying crane software. The results are as follows: 


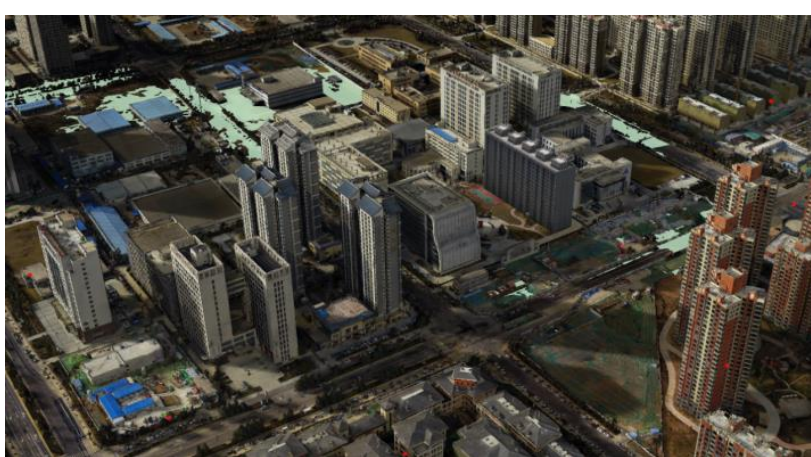

Figure 8. Rainstorm inundation scenario (simulate the scenario of heavy rain, the blue part is the flooded area)

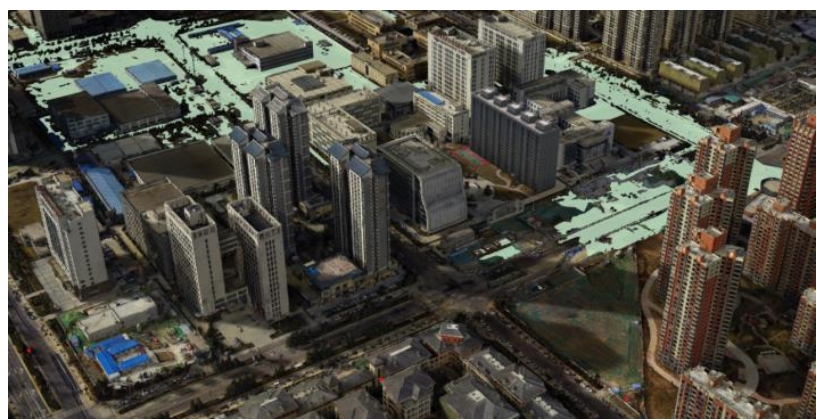

Figure 9.Flood inundation scenario (flood simulation scenario, the blue part is the flooded area)

By using this function, we simulate the surrounding situation of the building in rainstorm and flood, which can provide reference for flood disaster prevention and land management.

3.3.4 Fire Scenario Simulation: Fire is one of the biggest hidden dangers for the building and its internal personnel. How to simulate the scene of fire has always been a hot issue in cadastral management. We simulate the scene of fire in the building and carry out fire rescue by using the fly rope software. The results are as follows:

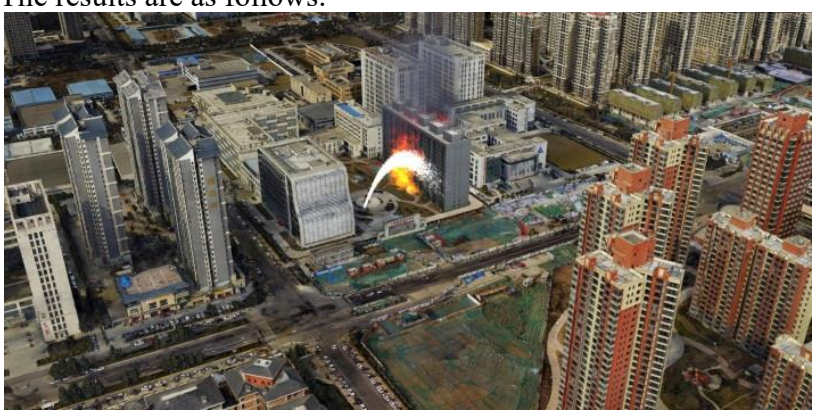

Figure 10. Simulation diagram of building fire

Using this function to vividly display the scene when the fire occurs can provide help for land management and emergency simulation. Compared with the two-dimensional scene technology, the technology can display the scene of the fire from a three-dimensional perspective, making the expression of information more intuitive and image.

3.3.5 Space measurement: In the traditional two-dimensional map, only the projection area of the building can be measured. In the land management, the space area of the planned building needs to be measured in addition to the projection area. Using the space area and space distance measurement function of the flyover software, the space area of the planned building and the space distance between the planned building and the surrounding buildings can be calculated, which can be used for land management and planning The analysis results are as follows:

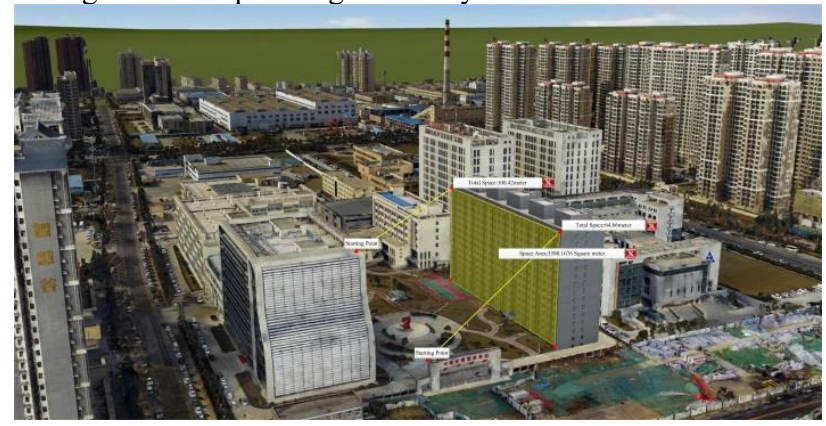

Figure 11. Space area and distance measurement

3.3.6 Snow simulation: In land management, a very important work is to simulate the impact of various rain and snow weather. With the support of three-dimensional real-world technology, we developed the rain and snow weather simulation function. The purpose is to provide effective help for land management and residents' lives through the simulation of rain and snow weather. The simulated snow weather scenario is as follows:

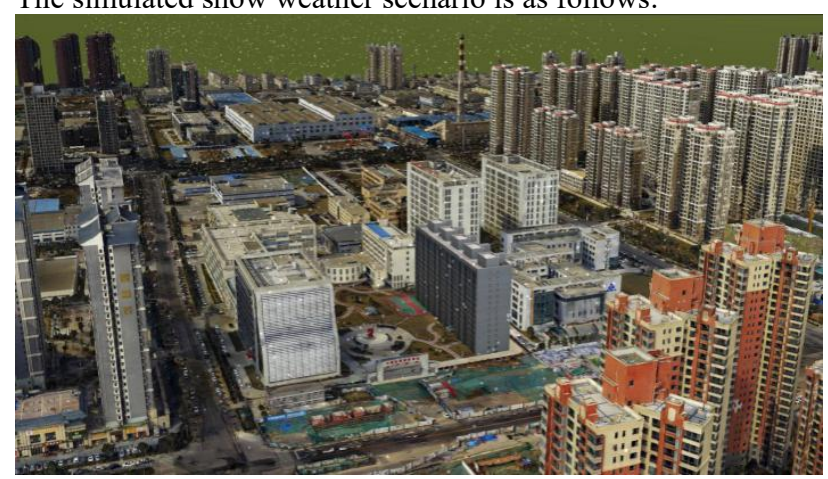

Figure 12. Snow scenario simulation

\section{CONCLUSION}

This paper introduces the new situation of three-dimensional land management, and introduces the concept of real threedimensional. In order to express the third dimension information of geographic information elements, this study adopts the method of three-dimensional real scene. Based on the comparison of twodimensional images, the advantages of real three-dimensional technology in land management are obtained. As shown in this paper, the three-dimensional reality platform can be used for sunshine analysis, visual analysis, submergence analysis, etc.

In order to support the application of land management in the complex background, the researchers of "Fly View" added the functions of model video projection, underground pipe network display, two or three-dimensional two screen comparison, fire scene simulation demonstration, etc. Through the analysis of sunshine, visual field and inundation of a new planning building in Xi'an, it shows that the software can better express threedimensional geographic information and promote the land management to a more intuitive and efficient direction.

There are several limitations in this study, such as difficulties in the follow-up development and application of 3D models, 
incomplete use of data, too many faces of 3D models, reduced effect after platform transplantation, large amount of data, lack of update and platform integration capabilities. In the future, with the solution of these problems one by one, we believe that real $3 \mathrm{D}$ can be applied to more fields to solve more practical production problems.

\section{ACKNOWLEDGEMENTS}

The authors would like to acknowledge the support by data providers and software developers.

\section{REFERENCES}

Guo ,R.Z., Luo P, Luo.T.W.,2018. Three-dimensional thinking of land management and cognition of land spatial resources . Geographical research,37(4), 649-658.

Qin R , Tian J , Reinartz P.,2016. 3D change detection Approaches and applications. ISPRS Journal of Photogrammetry and Remote Sensing, 122, 41-56.

Haim sandberg, three-dimensional division and registration of title to land: Legal aspects. 3D Cadastres. November 2001. 201209.

Zhang Y.L., Bao J.X., 1997. Analysis of urban land use in threedimensional model. Urban Development, (7), 28-29.

Lv X.W.,2017. Ferris wheel provide service in Central, Hongkong. http://news.xinhuanet.com/photo/2014-12/06/c 127281885_2. htm, 2017-12-06.

Deng Y, Cheng.2016. Anumba C . Mapping between BIM and 3D GIS in different levels of detail using schema mediation and instance comparison[J]. Automation in Construction, 2016, 67, $1-21$. 